\title{
Effect of Shaping Methods on the Mechanical Properties of AI-SiC Composite
}

\author{
M. Zakeri*, A. Vakili-Ahrari Rudi ${ }^{\mathrm{b}}$ \\ ${ }^{a}$ Ceramic Department, Materials and Energy Research Center, P.O. Box 31787/316, Karaj, Iran \\ 'Materials Science Department, Shiraz University, Shiraz, Iran
}

Received: June 17, 2012; Revised: May 7, 2013

\begin{abstract}
Al-SiC composites were successfully produced with improved mechanical properties. Effect of $\mathrm{SiC}$ content, its particles size and shaping method were investigated. Three shaping methods of conventional powder metallurgy (PM), hot press (HP) and hot extrusion (EX) were used. The hardness of the samples was measured by Vickers method. Tensile and compression tests were performed for the characterization of mechanical properties. Microstructure was monitored by optical microscopy. Maximum relative density (RD) was obtained for hot pressed samples. Higher SiC content with smaller particles size had the best effect on the mechanical properties such as yielding point (YP), ultimate tensile strength (UTS) and hardness. Maximum hardness (6.57 GPa) and UTS (212 MPa) were obtained for $\mathrm{Al}-20 \% \mathrm{SiC}$ with $\mathrm{SiC}$ mesh size of 1000. Maximum YP was obtained for $\mathrm{Al}-20 \% \mathrm{SiC}$ in compression test (143.64 MPa) that is larger than it in tensile test (117.96 MPa). Remarkable difference exists between HP and extrusion methods at higher SiC contents. The YP of EX samples are larger than HP samples. Strains at known stress (562 MPa) of EX samples are smaller than HP samples.
\end{abstract}

Keywords: metal matrix composite; extrusion; mechanical properties

\section{Inroduction}

Al based composite has been widely used in many fields owing to its excellent properties such as low weight, high special strength and stiffness, high electrical and thermal conductivity, low thermal expansion, good wear resistance and environmental corrosion resistance ${ }^{1,2}$. It is generally prepared by dispersion of ceramic particle like $\mathrm{SiC}, \mathrm{Si}_{3} \mathrm{~N}_{4}$, $\mathrm{A}_{2} \mathrm{O}_{3}$ or $\mathrm{TiC}$ in $\mathrm{Al}$ matrix and the most commonly used particle is $\mathrm{SiC}^{3-6}$.

Many methods have been used to prepare Al based composite. In the liquid methods, particles are added to liquid Al by stirring before casting. However, the difference in thermal expansion coefficients of the constituents and the poor wet-ability of molten $\mathrm{A} 1$ and $\mathrm{SiC}$ particles become an obstacle to the liquid method used for synthesizing Al-SiC composite. In addition, liquid metallurgy may lead to an undesirable reaction between $\mathrm{SiC}$ and molten $\mathrm{Al}$, producing brittle phase of $\mathrm{A}_{4} \mathrm{C}_{3}$ and $\mathrm{Si}^{[7]}$. Solid state method is another way of producing homogenous distribution of these hard particles. In this way, simple mixing of $\mathrm{Al}$ and $\mathrm{SiC}$ are performed by milling in different type of mills. There is no undesirable reaction and segregation between the components during producing with this method ${ }^{8}$.

Al-SiC composite powder can be sintered by several methods such as conventional pressure less sintering, hot pressing, hot extrusion, spark plasma sintering and etc ${ }^{9-14}$. Shaping method has very significant effect on physical and mechanical properties of this composite. Final densities of produced bulk Al-SiC as well as microstructure are two important affecting parameters on the mechanical and physical properties. Paydar showed that Al-SiC composite

*e-mail: M_zakeri@merc.ac.ir can be extruded at $400-500{ }^{\circ} \mathrm{C}$ with surface area reduction about $80 \%{ }^{15}$. Zamani also showed that extruding of this composite at temperatures below $350{ }^{\circ} \mathrm{C}$ leads to increasing of extruding pressure and defects in the produced final bulk composite $^{16}$. Hong et al have demonstrated the potential of making high strength $\mathrm{Al}-\mathrm{SiC}$ composites with reasonable ductility by resistance sintering of mechanically alloyed powders. It was found that the compressive yield stress and ultimate strength increases with increasing $\mathrm{SiC}$ volume fraction and decreasing $\mathrm{SiC}$ particle size, while the compressive failure strain shows the reverse trend with the variation in $\mathrm{SiC}$ particle size and content ${ }^{17}$. Sinter/hot isostatically pressed composites of up to $30 \mathrm{vol} \% \mathrm{SiC}$ were produced with a significant improvement in ductility and ultimate tensile strength compared with the other fabrication methods. The measured densities of the fabricated materials indicated that fully dense material was not achieved ${ }^{18}$.

In the present work, effect of shaping method and $\mathrm{SiC}$ particles size were studied on the mechanical properties of Al-SiC composite. Three different shaping methods of pressure less, hot press and hot extrusion as well as two $\mathrm{SiC}$ particles size were used.

\section{Experimental Procedures}

Al (99\%, 25 mm, Khorasan Metallurgy Co.) and SiC (99\%, 37 and $15 \mathrm{~mm}$, Merck) were used as starting materials for production of Al-SiC composites. Figure 1 shows the XRD pattern of the as-mixed materials. This pattern includes $\mathrm{Al}$ and $\mathrm{SiC}$ reflections. Morphology and Particles size of starting materials were also shown in Figure 2. A horizontal low energy ball mill was used for mixing of 
starting materials. Mixture of starting materials and stainless steel balls (20 balls with $8 \mathrm{~mm}$ diameter) were charged to stainless steel chamber. Ball milling was only performed for mixing of $\mathrm{Al}$ and $\mathrm{SiC}$ powders (15 min) with the rotational speed of $100 \mathrm{rpm}$. Five cylindrical samples $(\mathrm{d}=19.8 \mathrm{~mm}$, $\mathrm{h}=30 \mathrm{~mm}$ ) were produced by cold pressing at the pressure of $573 \mathrm{MPa}$. All samples were heat treated in atmosphere control furnace (Ar gas) at the temperature of $535{ }^{\circ} \mathrm{C}$ for $90 \mathrm{~min}$ with the heating rate of $10^{\circ} \mathrm{C} \cdot \mathrm{min}^{-1}$. One sample were cooled to room temperature and then characterized by the following methods. Two other samples, just hot

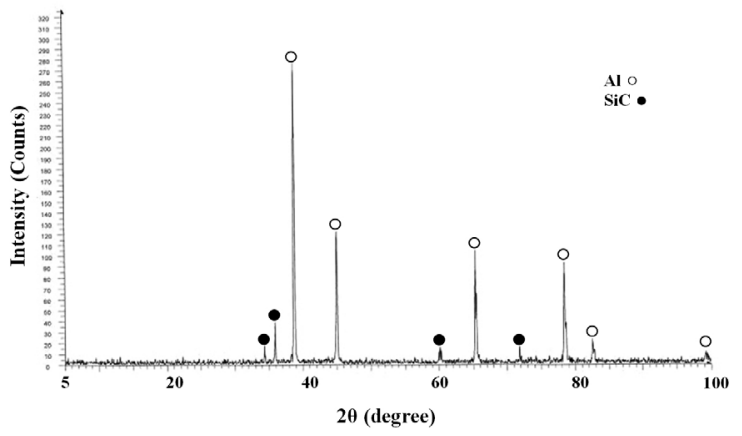

Figure 1. XRD pattern of the mixture of as-received materials.
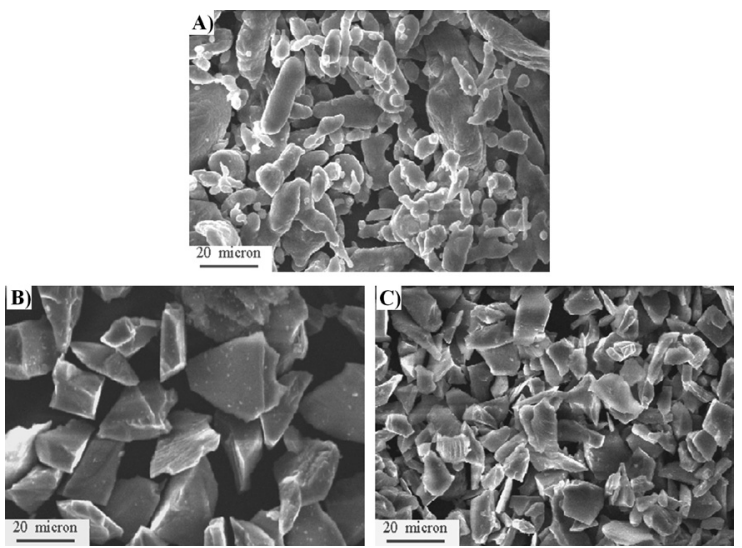

Figure 2. SEM images of as-received materials; A) Al, B) SiC (24 $\mu \mathrm{m}$, mesh 400) and C) SiC (10 mm, mesh 1000). pressed at the temperature of $535{ }^{\circ} \mathrm{C}$ with the pressure of $612 \mathrm{MPa}$. Two remained samples were hot extruded at the temperature of $535{ }^{\circ} \mathrm{C}$ for the surface area reduction of $84.3 \%$. Tensile specimens were fabricated from hot extruded bars on the basis of B557M-84 standard. Tensile and compression tests were performed by an universal testing machine (SANTAM200) with the head speed of $1 \mathrm{~mm} / \mathrm{min}$. Hardness of the samples was measured by Vickers method on the load of $10 \mathrm{~kg}$ and soaking time of $30 \mathrm{~s}$. Final density of bulk materials was measured by Archimedes method by immersion in distilled water. All samples were etched with $95 \% \mathrm{H}_{2} \mathrm{O}-5 \% \mathrm{HF}$ solution and then their microstructure was monitored by optical microscopy. Philips X-ray diffractometer with $\mathrm{Cu} \mathrm{K \alpha}$ (operating at $25 \mathrm{kV}$ and $30 \mathrm{~mA}$ ) was used for characterizing of starting materials.

\section{Results and Discussions}

Figure 1 shows the XRD pattern of the as mixed materials. Al-SiC composites with different SiC contents were produced. Morphology of these powders is shown in Figure 2. Al particles have very rounded and regular morphology with the mean particles size of $25 \mathrm{~mm}$. As seen in Figure 2B, C, SiC particles have an irregular and sharp edge that is due to the crushing during their production.

Al-SiC composite powders were hot extruded with different pressure (Table 1). Al had the minimum required pressure for hot extruding at $535{ }^{\circ} \mathrm{C}$. Higher $\mathrm{SiC}$ content led to the higher pressure as well as higher temperature. Extrusion pressure increases with decreasing $\mathrm{SiC}$ particles size. $\mathrm{SiC}$ is a brittle ceramic with no plastic deformation at ambient temperatures ${ }^{19}$. Introducing $\mathrm{SiC}$ to $\mathrm{Al}$ matrix leads to the decreasing of its plastic deformation. On the other hand, $\mathrm{Al}$ viscosity increases due to $\mathrm{SiC}$ particles, therefore more pressure and temperature are required for extruding of Al-SiC composite. Higher SiC content and its smaller particles have same effect on the extrusion pressure and temperature as discussed.

Relative density (RD) is the first characterization parameters for any shaping method. Each shaping methods that gives higher RD, it is better for production of bulk composite. RDs of Al-SiC composites with different SiC contents and particle size were shown after shaping with conventional powder metallurgy (PM), hot pressing (HP) and hot extrusion (EX) in Table 2. With comparison of

Table 1. Required pressure for hot extruding at different processing condition.

\begin{tabular}{ccccc}
\hline \multirow{2}{*}{$\begin{array}{c}\text { \% SiC } \\
(\text { vol. })\end{array}$} & $\begin{array}{c}\text { SiC particle } \\
\text { Size (mesh) }\end{array}$ & Temperature $\left({ }^{\circ} \mathbf{C}\right)$ & Reduction $(\boldsymbol{\%})$ & Pressure $(\mathbf{M P a}) \pm \mathbf{5}$ \\
\cline { 3 - 5 } & $\mathbf{0}$ & 535 & 835.31 & 313.45 \\
& $\mathbf{4 0 0}$ & 535 & 84.31 & 358.15 \\
$\mathbf{5}$ & $\mathbf{1 0 0 0}$ & 535 & 84.31 & 383.54 \\
& $\mathbf{4 0 0}$ & 535 & 84.31 & 408.65 \\
$\mathbf{1 0}$ & $\mathbf{1 0 0 0}$ & 570 & 84.31 & 414.78 \\
& $\mathbf{4 0 0}$ & 570 & 84.31 & 382.63 \\
\multirow{2}{*}{$\mathbf{1 5}$} & $\mathbf{1 0 0 0}$ & 570 & 84.31 & 394.88 \\
& $\mathbf{4 0 0}$ & 570 & 84.31 & 414.16 \\
\end{tabular}


Table 2. Al-SiC composite densities measured by Archimedes method.

\begin{tabular}{ccccc}
\hline \multirow{2}{*}{$\begin{array}{c}* \\
\text { \% }\end{array}$ (vol.) } & \multirow{2}{*}{$\begin{array}{c}\text { SiC particle } \\
\text { Size (mesh) }\end{array}$} & \multicolumn{3}{c}{ Density \%0.2 } \\
\cline { 3 - 5 } & ---- & 99.86 & 80.11 & 99.62 \\
0 & 400 & 99.94 & 84.36 & 99.21 \\
& 1000 & 99.9 & 86.68 & 99.82 \\
5 & 400 & 99.97 & 85.15 & 99.67 \\
& 1000 & 99.58 & 88.35 & 99.39 \\
10 & 400 & 99.82 & 86.25 & 99.42 \\
& 1000 & 99.62 & 86.45 & 99.67 \\
15 & 400 & 99.63 & 86.36 & 99.34 \\
& 1000 & 99.8 & 86.4 & 99.69 \\
\hline \multirow{2}{*}{20} & & & & \\
& &
\end{tabular}
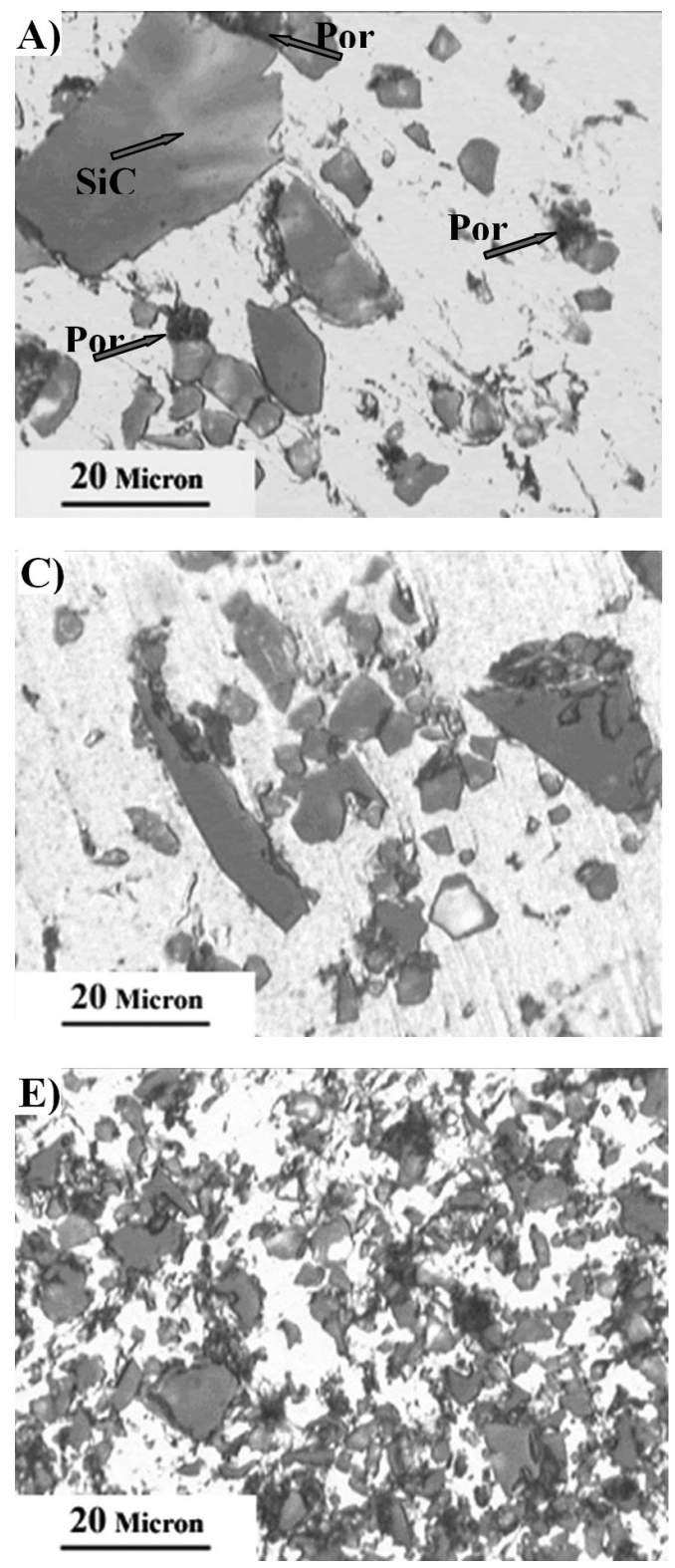

these methods, it can be concluded that RD in PM is lower than HP and EX. PM is a pressure less sintering method that there is no pressure during heating, therefore, sintering process cannot be completely performed. The RD of Al-SiC composites that produced with HP were higher than EX. It seems that the static behavior of HP method leads to more plastic deformation and mass transformation. On the other hand, dynamic manner of extrusion method with the shorter process time reduces the plastic deformation and resulted RD. SiC particle size and its contents had no considerable effect on RD.

Microstructure of Al-SiC composites were shown in Figure 3. Figures $3 \mathrm{~A}-\mathrm{C}$ are attributed to PM, EX and HP samples with $10 \% \mathrm{SiC}$, respectively. In the PM sample, some pores can be seen in the microstructure due to its
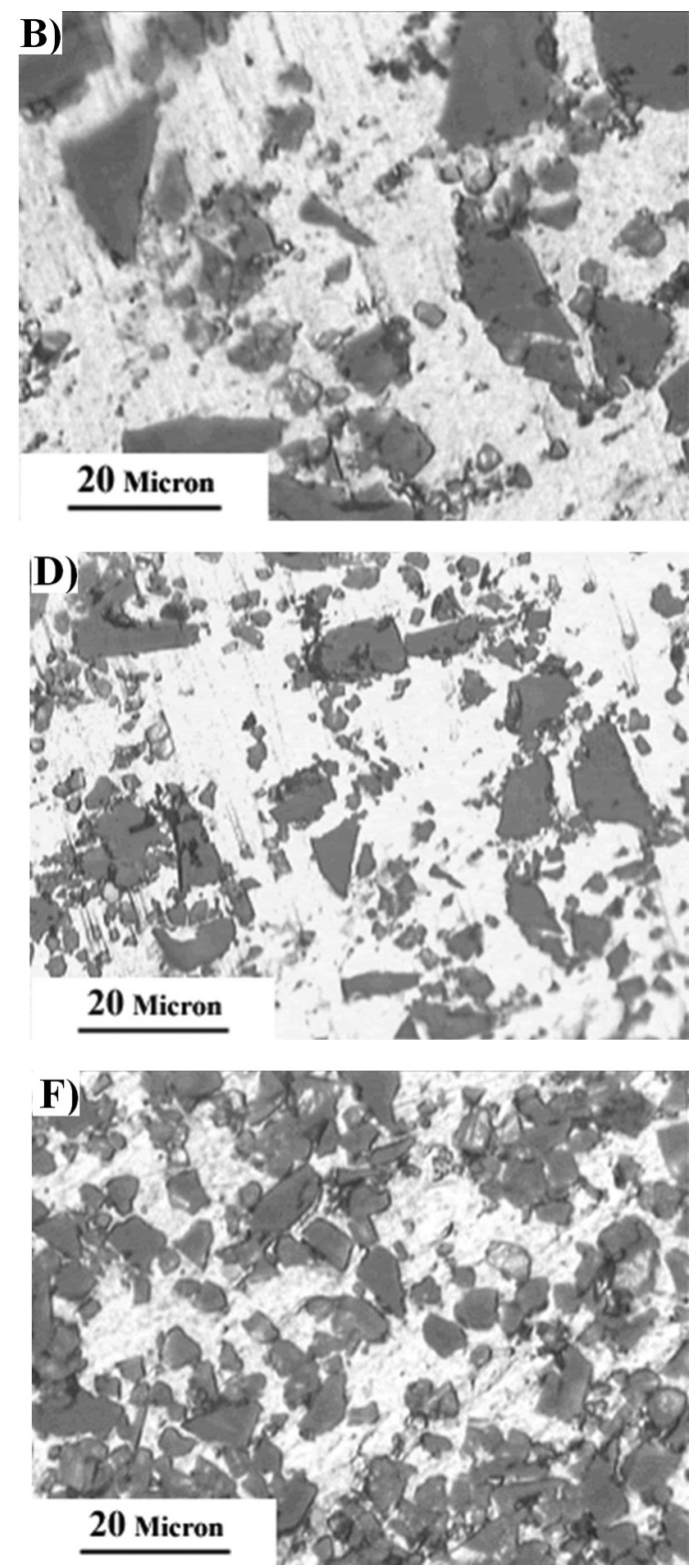

Figure 3. Optical microscopy images of Al-SiC composites; A) $10 \% \mathrm{SiC}$ mesh 400, P.M., B) $10 \% \mathrm{SiC}$ mesh 400, EX., C) $10 \% \mathrm{SiC}$ mesh 400, H.P., D) $10 \% \mathrm{SiC}$ mesh 1000, EX., E) $15 \% \mathrm{SiC}$ mesh 1000 , EX., and F) $20 \% \mathrm{SiC}$ mesh 1000 , H.P. 
low RD. But, approximately, there is no pore in the HP and EX samples microstructures due to their higher RD. Figure 3D shows the microstructure of $\mathrm{Al}-10 \% \mathrm{SiC}$ with the $\mathrm{SiC}$ mesh size of 1000 . Comparison of this image with Figure 2B ( $\mathrm{SiC}$ size is mesh 400) shows that $\mathrm{SiC}$ particles have better distribution in smaller size. Figures $3 \mathrm{E}, \mathrm{F}$ show the microstructures of $\mathrm{Al}-15 \% \mathrm{SiC}$ with $\mathrm{EX}$ and $\mathrm{Al}-20 \% \mathrm{SiC}$ with HP methods, respectively. Discontinuity of Al matrix increases with increasing $\mathrm{SiC}$ content that decreases the ductility and strength of this composite. These effects can be seen in the results of tensile experiments.

Vickers hardness of Al-SiC composites with different $\mathrm{SiC}$ contents and particles sizes were presented in Table 3. Pure bulk Al has the minimum hardness in all three methods. As seen, those samples that were produced by PM method have lower hardness in compare with HP and EX methods. As discussed before, sintering process was not completed in PM process and samples have more porosity that leads to the more plastic deformation under indent loading. Higher $\mathrm{SiC}$ content with smaller particles size led to the harder composite. High hardness of $\mathrm{SiC}$ is the main reason of hardness increasing, but also, low plastic deformation of composite due to existence of $\mathrm{SiC}$ reinforcements is another reason for this improvement in hardness. Maximum hardness of $7.45 \mathrm{GPa}$ was obtained for $\mathrm{Al}-20 \% \mathrm{SiC}$ that was produced by HP method with SiC mesh size 1000. Comparison of this hardness with pure HP and EX aluminum shows that the hardness increased about 60 and $145 \%$, respectively.

Figure 4 shows the effect of $\mathrm{SiC}$ content and its particles size on yielding point (YP), ultimate tensile strength (UTS) and elongation of Al-SiC composite that produced with EX method. As seen, YP and UTS increase with increasing $\mathrm{SiC}$ content. Higher $\mathrm{SiC}$ content leads to the more $\mathrm{SiC}$ particles in the $\mathrm{Al}$ matrix and less plastic deformation. On the other hand, SiC particles are a barrier for movement of dislocations in $\mathrm{Al}$ matrix; therefore for dislocation gliding between these $\mathrm{SiC}$ reinforcements, higher flow stress was required. SiC particles size has a same effect as $\mathrm{SiC}$ content. Smaller SiC particle size means more particles in Al matrix with smaller space between them. On the basis of Orown mechanism, the flow stress for dislocation gliding increases with decreasing reinforcements distance ${ }^{20}$. Higher $\mathrm{SiC}$ content with smaller particles size led to the lower elongation that is due to the discontinuity of $\mathrm{Al}$ matrix. Lower $\mathrm{Al}$ content and its discontinuity led to the lower plastic deformation and elongation. In general, Higher $\mathrm{SiC}$ content with smaller particle size led to the higher strength with lower ductility Al-SiC composites. UTS of Al-20\%SiC with the SiC mesh sizes of 400 and 1000 were increased in compare with pure $\mathrm{Al}$ about 18 and $32 \%$, respectively. This effect for YP was 32 and $36 \%$ correspondingly. Elongations of Al-20\% SiC composite with the $\mathrm{SiC}$ mesh size of 400 and 1000 were significantly decreased to 75 and $83 \%$, in that order.

Compression test was performed on the cylindrical hot pressed samples with the same height and diameter $(8 \mathrm{~mm})$. Yielding point and strain at known stress (585 MPa) of these samples are shown in Figure 5. SiC content and its particles size had a same effect on YP as tensile tests. But maximum YP of Al-20\%SiC in compression test (143.64 MPa) is larger than it in tensile test (117.96 MPa). There is some minor porosity in HP samples (refer to Table 2). These porosities act as crack nucleation in tensile test that leads to lower YP. On the other hands, the applied pressure during compression test leads to closing of these porosities. There is no fracture on compression test of ductile materials; therefore elongation of these materials cannot be measured. There is one approach to measure the elongation by measurement of the sample strain at arbitrary known stress. Measurement

Table 3. Vickers hardness number of Al-SiC composites at different processing condition.

\begin{tabular}{|c|c|c|c|c|}
\hline \multirow{2}{*}{$\begin{array}{r}\% \mathrm{SiC} \\
\text { (vol.) }\end{array}$} & \multirow{2}{*}{$\begin{array}{l}\text { SiC particle } \\
\text { Size (mesh) }\end{array}$} & \multicolumn{3}{|c|}{$\begin{array}{l}\text { Vickers Hardness Number }\left(\mathrm{HV}_{10}\right) \\
(\mathrm{GPa}) \mathbf{0 . 1}\end{array}$} \\
\hline & & H.P & P.M. & EX. \\
\hline 0 & ---- & 4.67 & & 4.67 \\
\hline \multirow{2}{*}{5} & 400 & & & \\
\hline & 1000 & & & \\
\hline \multirow{2}{*}{10} & 400 & & & \\
\hline & 1000 & & & \\
\hline \multirow{2}{*}{15} & 400 & & & \\
\hline & 1000 & & & \\
\hline \multirow{2}{*}{20} & 400 & & & \\
\hline & 1000 & & & \\
\hline
\end{tabular}

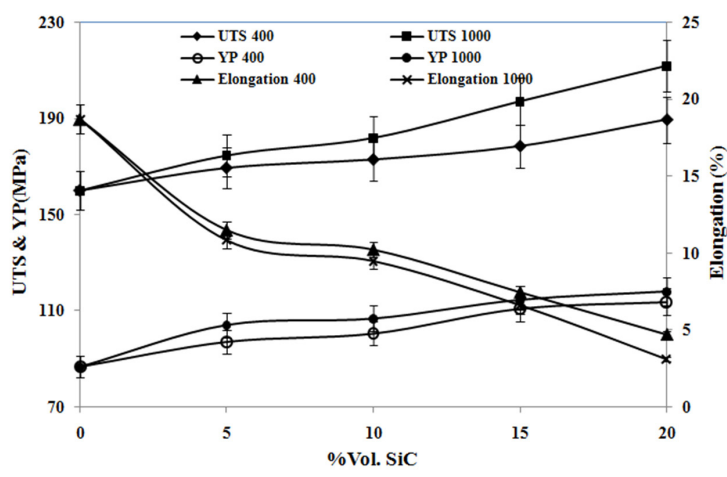

Figure 4. Ultimate tensile strength, yielding point and elongation from tensile experiments of hot extruded $\mathrm{Al}-\mathrm{SiC}$ composites.

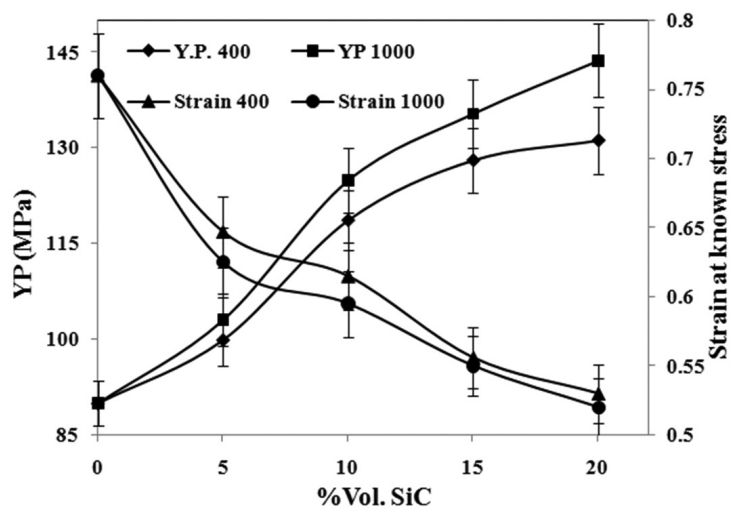

Figure 5. Yield point and strain under known stress (585 MPa) of hot extruded $\mathrm{Al}-\mathrm{SiC}$ composites from compression experiments. 
of strain of the samples at the stress of $585 \mathrm{MPa}$ shows that higher $\mathrm{SiC}$ content with smaller particles size decreases this strain. On the other hand, $20 \%$ SiC led to the $31.5 \%$ decrease of this strain in compare with pure Al that means it's ductility significantly decreased.

HP and EX methods were compared by compression test. As seen in Figure 6, the YP of EX samples are larger than HP samples. Strains at known stress (562 MPa) of

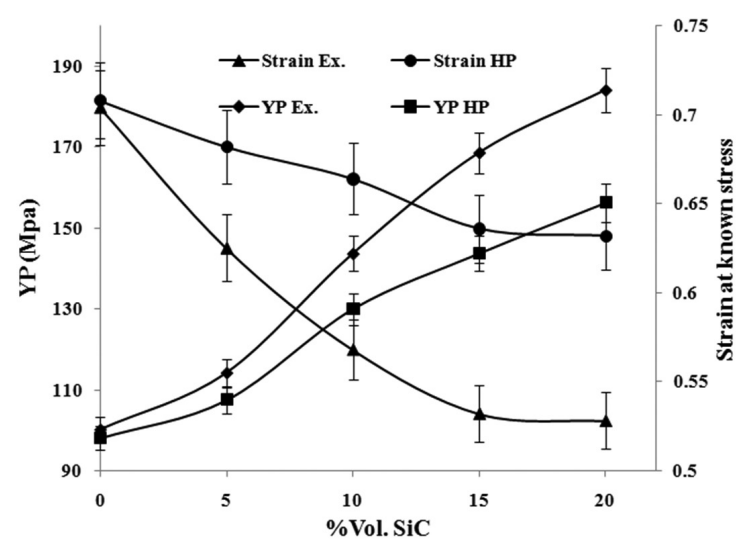

Figure 6. Effect of shaping method on compressive properties of Al-SiC composite.

Table 4. Difference between YP and strain of HP and EX samples.

\begin{tabular}{cccccc}
\hline \% SiC & $\mathbf{0}$ & $\mathbf{5}$ & $\mathbf{1 0}$ & $\mathbf{1 5}$ & $\mathbf{2 0}$ \\
\hline & 0 & 6.29 & 10.57 & 17.40 & 17.91 \\
& 0 & 9.12 & 16.90 & 19.55 & 19.70 \\
\hline
\end{tabular}

\section{References}

1. Jung HK, Cheong YM, Ryu HJ and Hong SH. Analysis of anisotropy in elastic constants of SiCp/2124 Al metal matrix composites. Scripta Materialia. 1999; 41:1261-67. http:// dx.doi.org/10.1016/S1359-6462(99)00295-X

2. Prasad SV and Asthana R. Aluminum metal-matrix composites for automotive applications: Tribological considerations. Tribology Letters. 2004; 17(3):445-453. http://dx.doi. org/10.1023/B:TRIL.0000044492.91991.f3

3. Raju KS, Bhanu Prasad VV, Rudrakshi GB and Ojha $\mathrm{SN}$. PM processing of $\mathrm{Al}-\mathrm{Al}_{2} \mathrm{O}_{3}$ composites and their characterization. Powder Metallurgy. 2003; 46:219-23. http:// dx.doi.org/10.1179/003258903225008553 http://dx.doi. org/10.1179/003258903225008553

4. Kim KT, Lee SC and Ryu HS. Densification behavior of aluminum alloy powder mixed with zirconia powder inclusion under cold compaction. Materials Science and Engineering: A. 2003; 340:41-8. http://dx.doi.org/10.1016/ S0921-5093(02)00175-2

5. Kang Y-C and Chan SL. Tensile properties of nanometric $\mathrm{Al}_{2} \mathrm{O}_{3}$ particulate-reinforced aluminum matrix composites. Materials Chemistry and Physics. 2004; 85(2-3):438-443. http://dx.doi. org/10.1016/j.matchemphys.2004.02.002

6. Jiang G, Daehn GS and Wagoner RH. Observations on densification of $\mathrm{Al}-\mathrm{Al}_{2} \mathrm{O}_{3}$ composite powder compacts by pressure cycling. Powder Metallurgy. 2003; 46:78-82. http:// dx.doi.org/10.1179/003258903225010505
EX samples are smaller than HP samples. Ductility of Al-20\%SiC composites was decreased about 25 and $11 \%$ for EX and HP samples, respectively in compare with pure Al. On the other hand, the ductility of HP samples is more than EX samples. It seems that this is attributed to dynamic behavior of EX method. On the other hand, static manner of HP method leads to remaining some stress in samples. This stress will decrease the YP and brittleness of HP samples. Difference of YP and strain of HP and EX samples were calculated at different $\mathrm{SiC}$ contents (Table 4). As seen, these values increase with increasing $\mathrm{SiC}$ content. A remarkable difference exists between HP and EX methods at higher $\mathrm{SiC}$ contents.

\section{Conclusion}

Al-SiC composites with improved mechanical properties were produced by three shaping methods. Effects of $\mathrm{SiC}$ content and its particles size were investigated. Results showed that the HP method can produce maximum RD with minimum porosity. Higher SiC content with smaller particles size led to higher strength on the basis of tensile and experiment tests. Brittleness of Al-SiC composite increases at higher $\mathrm{SiC}$ content. Maximum hardness of $6.57 \mathrm{GPa}$ was obtained for $\mathrm{Al}-20 \% \mathrm{SiC}$ with $\mathrm{SiC}$ mesh size of 1000 . UTS of $\mathrm{Al}-20 \% \mathrm{SiC}$ with the $\mathrm{SiC}$ mesh sizes of 400 and 1000 were increased in compare with pure $\mathrm{Al}$ about 18 and $32 \%$, respectively. Maximum YP was obtained for $\mathrm{Al}-20 \% \mathrm{SiC}$ in compression test $(143.64 \mathrm{MPa})$ that is larger than it in tensile test (117.96 MPa). A remarkable difference exists between HP and EX methods at higher SiC contents. The YP of EX samples are larger than HP samples. Strains at known stress (562 MPa) of EX samples are smaller than HP samples.

7. Wan-li G. Bulk Al-SiC nanocomposite prepared by ball milling and hot pressing method. Transactions of Nonferrous Metals Society of China. 2006; 16:398-401. http://dx.doi.org/10.1016/ S1003-6326(06)60219-7

8. Vakili-Ahrari Roudi A. Fabrication of Al/SiC Nanocomposite and Investigation of its Mechanical Properties. [Thesis]. Shiraz university, 2005.

9. Smagorinski ME, Tsantrizos PG, Grenier S, Cavasin A, Brzezinski T and Kim G. The properties and microstructure of Al-based composites reinforced with ceramic Particles. Materials Science and Engineering: A. 1998; 244:86-90. http:// dx.doi.org/10.1016/S0921-5093(97)00830-7

10. Zhang XN, Geng L and Xu B. Compressive behaviour of Al-based hybrid composites reinforced with $\mathrm{SiC}$ whiskers and $\mathrm{SiC}$ nanoparticles. Materials Chemistry and Physics. 2007; 101:242-246. http://dx.doi.org/10.1016/j. matchemphys.2006.04.004

11. Welham NJ, Wills PE and Kerr T. Mechanochemical Formation of Metal-Ceramic Composites. Journal of American Ceramic Society. 2000; 83:33-40. http://dx.doi. org/10.1111/j.1151-2916.2000.tb01144.x

12. Kamrani S, Riedel R, Seyed Reihani SM and Kleebe HJ. Effect of Reinforcement Volume Fraction on the Mechanical Properties of Al-SiC Nanocomposites Produced by Mechanical Alloying and Consolidation. Journal of Composite Materials. 2010; 44 (3) 313-326. http://dx.doi.org/10.1177/0021998309347570 
13. Hafizpour HR, Sanjari M and Simchi A. Analysis of the effect of reinforcement particles on the compressibility of Al-SiC composite powders using a neural network model. Materials \& Design. 2009; 30(5):1518-1523. http://dx.doi.org/10.1016/j. matdes.2008.07.052

14. Cambronero LEG, Sanchez E, Ruiz-Roman JM and RuizPrieto JM. Mechanical charactrisation of AA 7015 Aluminum Alloy Reinforced with Ceramics. Journal of Materials Processing Technology. 2003; 143-144:378-383. http://dx.doi. org/10.1016/S0924-0136(03)00424-2

15. Paydar MH. Fabrication of Al-SiC composite and investigation of its creep behavior. [Thesis]. Shiraz University; 1996.

16. Zamani S. Investigation of different parameters on creep behavior of Al-SiC composite. [Thesis]. Shiraz University; 1999.
17. Hong SJ and Kao PW. Mechanical properties of AlSiCcomposites made by resistance sintering of mechanically alloyed powders. Materials Science and Engineering: A. 1991; 148:189-195. http://dx.doi.org/10.1016/09215093(91)90821-4

18. Ling CP, Bush MB, Perera DS. The effect of fabrication techniques on the properties of Al-SiC composites. Journal of Materials Processing Technology. 1995; 48:325-331. http:// dx.doi.org/10.1016/0924-0136(94)01665-N

19. Okada A. Handbook of Advanced Ceramics. 2003. p. 417-443. http://dx.doi.org/10.1016/B978-012654640-8/50042-0

20. Dieter GE. Mechanical metallurgy. SI metric ed. London: McGraw-Hill; 1988. 